\title{
Assessment of hybrid renewable power sources for rural electrification in Malaysia
}

\begin{abstract}
Research works on hybrid renewable energy systems for rural electrifications have been quite intensive in recent years. Traditional power systems for remote or rural areas are based on fossil fuels. After addition of renewable energy resources, solar energy applications have become popular in remote energy systems. The recent study and research works show that adding other possible renewable energy resources such as wind, hydro and biomass could make a hybrid system more cost-effective and environmentally friendly. Hence, in the present study, an overview of applied hybrid renewable energy system (HRES) for worldwide villages with special attention on Malaysia has been proposed to help present and future works for better achievement in this field. Furthermore, a proper design and analysis for one village in Malaysia based on proposed combination is provided. The results show that combination of photovoltaic-wind -battery is defined as a cost-effective HRES for villages in Malaysia.
\end{abstract}

Keyword: Renewable energy; Photovoltaic; Malaysia; Hybrid renewable energy system; Rural electrification 